\title{
Comparing the role of Ginkgolide B and Ginkgolide $K$ on cultured astrocytes exposed to oxygen-glucose deprivation
}

\author{
WEN-BO YU ${ }^{1}$, LIANG CAO $^{2}$, YAN-YIN ZHAO ${ }^{1}$, WEI XIAO ${ }^{2}$ and BAO-GUO XIAO ${ }^{1}$ \\ ${ }^{1}$ Department of Neurology, Huashan Hospital, State Key Laboratory of Medical Neurobiology, Fudan University, \\ Shanghai 200040; ${ }^{2}$ State Key Laboratory of New-Tech for Chinese Medicine Pharmaceutical Process, \\ Lianyungang, Jiangsu 222047, P.R. China
}

Received January 17, 2018; Accepted July 27, 2018

DOI: $10.3892 / \mathrm{mmr} .2018 .9450$

\begin{abstract}
Ginkgolide B (GB) and ginkgolide K (GK) are two main active monomers of ginkgolides that present a unique group of diterpenes found naturally in the leaves of the Ginkgo biloba tree. Astrocytes are the most abundant cell type within the central nervous system (CNS) and serve essential roles in maintaining healthy brain function. The present study compared the biological effects of GB and GK on astrocytes exposed to oxygen-glucose deprivation (OGD). The results demonstrated that GB and GK exhibit many different actions. The level of the platelet-activating factor (PAF) was elevated on astrocytes exposed to OGD, and inhibited by GB and GK treatment. Although GB and GK inhibited the expression of $\mathrm{p}-\mathrm{NF}-\kappa \mathrm{B} / \mathrm{p} 65$, GK exerted stronger anti-inflammatory and antioxidant effects on astrocytes exposed to OGD than GB by inhibiting interleukin (IL)-6 and tumor necrosis factor- $\alpha$, and inducing IL-10 and the nuclear factor-erythroid 2-related factor 2/HO-1 signaling pathway. When compared with GB treatment, GK treatment maintained high levels of phosphoinositide 3-kinase/phosphorylated-protein kinase B expression, and induced a marked upregulation of Wnt family member 1 and brain derived neurotrophic factor, indicating that GK, as a natural plant compound, may have more attractive prospects for clinical application in the treatment of neurological disorders than GB.
\end{abstract}

Correspondence to: Professor Bao-Guo Xiao, Department of Neurology, Huashan Hospital, State Key Laboratory of Medical Neurobiology, Fudan University, 12 Wulumuqi Middle Road, Shanghai 200040, P.R. China

E-mail: bgxiao@shmu.edu.cn

Professor Wei Xiao, State Key Laboratory of New-Tech for Chinese Medicine Pharmaceutical Process, 58 Haichang Road, Lianyungang, Jiangsu 222047, P.R. China

E-mail: kanionlunwen@163.com

Key words: ginkgolide B, ginkgolide $\mathrm{K}$, astrocyte, oxygen-glucose deprivation

\section{Introduction}

Astrocytes are one of the most abundant cell types within the central nervous system (CNS) and play essential roles in maintaining healthy brain function, including providing structural support, regulating blood flow, modulating neuronal metabolism, and maintaining the extracellular microenvironment $(1,2)$. They are also a critical structural and functional part of synapses $(3,4)$ and the neurovascular unit $(5,6)$, and communicate with neurons and endothelial cells $(7,8)$, contributing to angiogenesis, neurogenesis, and synaptic plasticity. Additionally, astrocytes are primary responders to CNS injury such as infection, trauma, ischemia and neurodegenerative disease, where they either exert critical beneficial neuroprotective and neurorestorative effects or play detrimental roles by triggering glutamate excitotoxicity, inflammatory molecule release and oxidative stress (9-11). Thus, to develop successful clinical neuroprotective and neurorestorative strategies, further investigation targeted on astrocytes is need for a promising therapeutic target of pharmacological and cell-based approaches.

Ginkgolide extracted from the Ginkgo biloba leaves have been documented to possess a broad spectrum of pharmacological properties, including neuroprotection, anticancer, cardioprotection and stress alleviating, and potential benefits against ischemic stroke, Alzheimer's disease $(12,13)$ and psychiatric disorders (14). Ginkgolide B (GB) is a primary active monomer of ginkgolide that inhibits the activity of platelet-activating factor (PAF) by binding to its membrane receptor (15). BN 52021 has a protective effect against myocardial ischemia/reperfusion (IR) dysfunction (16), cerebral ischemic damage and the neurological deficits of mice after middle cerebral artery occlusion (MCAO) (17). GB also efficiently alleviates spinal cord injury by inhibiting STAT1 expression (18) and protects human umbilical vein endothelial cells via pregnane $X$ receptor activation (19). GB treatment has been shown to significantly decrease intracranial pressure (ICP) and improve cerebral perfusion pressure (CPP) as well as reduce the lactate/pyruvate ratio (LPR) in patients with non-traumatic severe acute hemorrhagic stroke (20). Therefore, GB appears to benefit tissue protection by different mechanisms in several disorders.

Ginkgolide K (GK, C20H22O9 as shown in Fig. 1, with one more hydroxyls than GB), a derivative compound of GB and 
isolated from the leaves of the Ginkgo biloba, can markedly improve neural cytotoxicity and shows neuroprotective effects. GK has been reported to exhibit protective effects against glutamate cytotoxicity and $\mathrm{H}_{2} \mathrm{O}_{2}$-induced cytotoxicity in $\mathrm{PC1} 2$ cells $(21,22)$. GK also protects the heart against endoplasmic reticulum stress by activating the inositol-requiring enzyme $1 \mathrm{a} / \mathrm{X}$ box-binding protein-1 pathway (23), and against acute ischemic stroke caused by MCAO through antioxidative effects (24). To the best of our knowledge, there has been no comparative study of GB and GK or a study examining the role of GK on astrocytes exposed to oxygen-glucose deprivation (OGD).

However, whether GK can also exert effects on astrocytes, which are the most abundant cell population in the brain, is unknown. In the present study, we used primary astrocytes that were exposed to OGD for a cell model of ischemic stroke to evaluate how GK influences astrocyte function to potentially affect neuronal survival and recovery after ischemia.

\section{Materials and methods}

Ethical Statement. The present study was approved by the Ethics Committee of Fudan University (Shanghai, China), based on the recommendations established in the Guide for the National Science Council of the Republic of China. The protocols were approved by the Ethics Committee of Fudan University. The approval number from the IRB is '20150572A259'. This manuscript was written in accordance with the ARRIVE (Animal Research: Reporting in vivo Experiments) guidelines. Pregnant C57/B6 female mice were housed 1 per cage in a temperature-controlled room $\left(22^{\circ} \mathrm{C} \pm 1^{\circ} \mathrm{C}\right)$ under a 12 -hour dark/light cycle with free access to water and food in the Animal House of Fudan University. Newborn mice $(<24 \mathrm{~h})$ were sacrificed by decapitation, and the brains were removed.

Drugs and reagents. GB and GK were extracted and separated from ginkgo leaf by recrystallization and high-performance liquid chromatography (HPLC) separation and had a purity $>98 \%$. GB and GK were dissolved in dimethyl sulfoxide (DMSO; Sigma-Aldrich, Merck KGaA, Darmstadt, Germany) before the experiment. Dulbecco's modified Eagle's medium (DMEM), fetal bovine serum, $100 \mathrm{U} / \mathrm{ml}$ penicillin, and $100 \mu \mathrm{g} / \mathrm{ml}$ streptomycin were obtained from Gibco (Thermo Fisher Scientific, Inc., Waltham, MA, USA). All other reagents were from Sigma-Aldrich (Merck KGaA) unless otherwise stated.

Primary astrocyte culture and treatment. Primary cortical astrocytes were prepared from newborn mice at postnatal $24 \mathrm{~h}$ as previously described with minor modifications (25). Briefly, meninges-free cortices were cut into small cubes $\left(<1 \mathrm{~mm}^{3}\right)$ and digested with $0.25 \%$ trypsin at $37^{\circ} \mathrm{C}$ for $15 \mathrm{~min}$. The suspension of tissue fragments was passed through a $40-\mu \mathrm{m}$ cell strainer and allowed pre-adherence for $1 \mathrm{~h}$ to remove contamination from fibroblasts. The supernatant containing unattached cells was transferred to 25 or $75-\mathrm{cm}^{2}$ flasks (Corning, Inc., Corning, $\mathrm{NY}, \mathrm{USA}$ ) and cultured in an incubator with $5 \% \mathrm{CO}_{2}$ at $37^{\circ} \mathrm{C}$. The culture medium was changed with complete DMEM every 3-4 days. When the cultures reached $80-90 \%$ confluence, cells were sub-cultured for another 7 days before they were used. The purity of astrocytes in cultures was determined by staining for astrocytic marker glial fibrillary acidic protein (GFAP). More than $95 \%$ cells showed GFAP immunoreactivity in the cultures.

For OGD, cells were exposed to $95 \%$ nitrogen and $5 \% \mathrm{CO}_{2}$ maintained by constant gas flow at $37^{\circ} \mathrm{C}$ in all experiments (Forma Anaerobic System; Thermo Fisher Scientific, Inc.). Oxygen tension was maintained at $1-2 \%$ during the duration of the test. The media used in these experiments consisted of sugar-free culture medium containing salts, $10 \%$ fetal bovine serum, $100 \mathrm{U} / \mathrm{ml}$ penicillin, and $100 \mu \mathrm{g} / \mathrm{ml}$ streptomycin. Control groups were grown under standard culture conditions $\left(5 \% \mathrm{CO}_{2}\right.$ and $95 \%$ oxygen).

Astrocytes were exposed to OGD for $3 \mathrm{~h}$ followed by re-oxygenation for $24 \mathrm{~h}$. Before re-oxygenation, cells were washed in PBS, and the medium was replaced with complete DMEM containing glucose and 10\% fetal bovine serum. At the same time, GB and GK $(30 \mu \mathrm{g} / \mathrm{ml}$, dissolved in DMSO) were added to different cell cultures (ratio of GB/GK: medium=1:1,000). The same volume of DMSO was added as a control.

In the preliminary experiments, we used the 5H-SY5Y/A53T cells to observe the effect of GK with different concentrations $(2,10,30$ and $50 \mathrm{ug} / \mathrm{ml})$. The results showed that only high concentrations (30 and $50 \mathrm{ug} / \mathrm{ml}$ ) of GK can promote autophagy to degrade alpha-synuclein and induce the BDNF in the 5H-SY5Y/A53T cells. Therefore, in this study, we used $30 \mathrm{ug} / \mathrm{ml}$ of GK.

Morphological observation. For astrocyte morphology observation, astrocytes were washed in PBS, fixed with 4\% paraformaldehyde and stained with the anti-GFAP antibody. The cells were observed under a fluorescence microscope (BX60; Olympus Imaging America Inc., Center Valley, PA, USA).

Cell viability. The cell viability was measured using an 3-(4,5-dimethylthazol-2-yl)-2,5-diphenyltetrazolium bromide (MTT) assay. Briefly, a total of $10 \mu 1$ MTT $(5 \mathrm{mg} / \mathrm{ml}$ in PBS, BDH Chemicals) was added to each 96-well containing $200 \mu 1$ medium before the conduction of incubation at $37^{\circ} \mathrm{C}$ for $4 \mathrm{~h}$. The reaction was stopped by the addition of $100 \mu 1$ DMSO. The optical density (OD) was measured at $570 \mathrm{~nm}$ by a Synergy H1 microplate reader (BioTek Instruments, Inc., Winooski, VT, USA), and the results were expressed as an OD value.

$L D H$ release. Cell cytotoxicity was quantitatively assessed by measuring the activity of LDH released from the damaged cells into the culture medium. At the end of culture, the supernatants that contained detached cells were centrifuged at $2000 \mathrm{rpm}$ for $10 \mathrm{~min}$. The supernatant was then used for the LDH activity assay. The enzyme was quantified by using an assay kit according to the manufacturer's protocol. The absorbance of the samples was read at $440 \mathrm{~nm}$ using a microplate reader (Synergy H1; BioTek Instruments, Inc.). The LDH release was expressed as a percentage of experimental vs. $100 \%$ damaged cells.

Enzyme-linked immunosorbent assay (ELISA). The quantity of interleukin (IL)-1 $\beta$, IL-6, IL-10, TNF- $\alpha$, and PAF released 
A

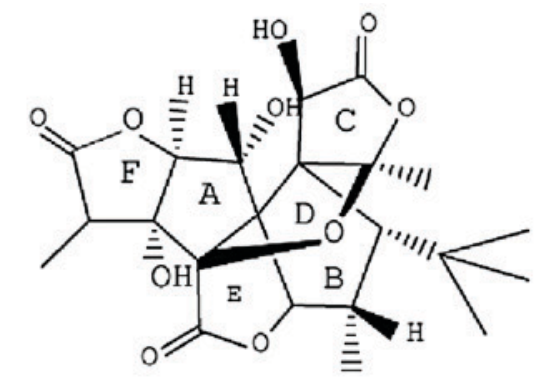

Ginkgolide B

B

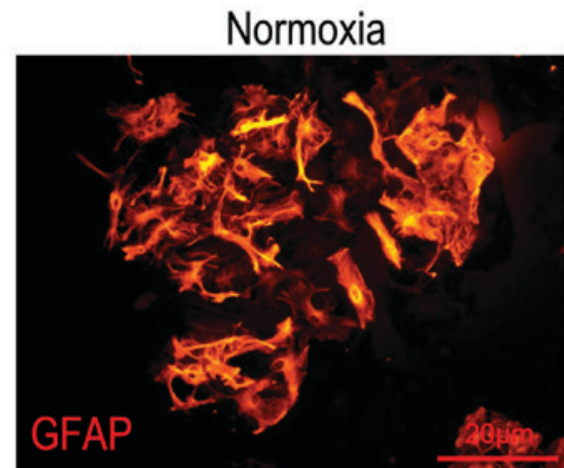

$$
\mathrm{OGD}+\mathrm{GB}
$$

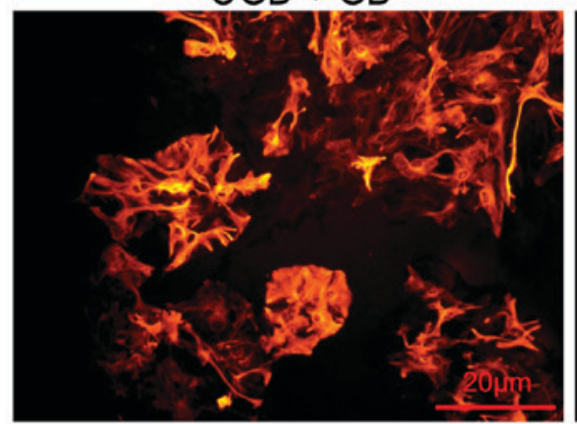

C

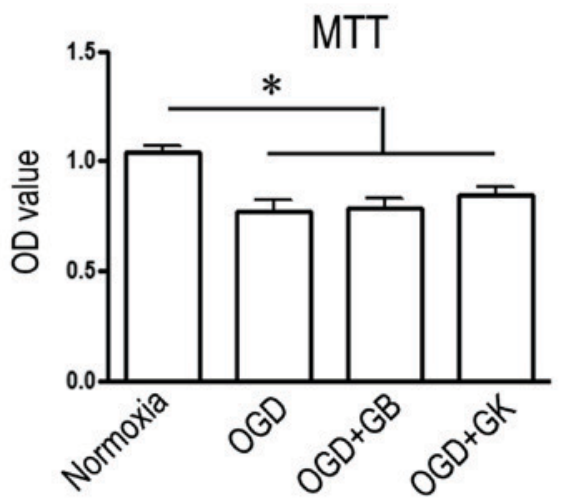

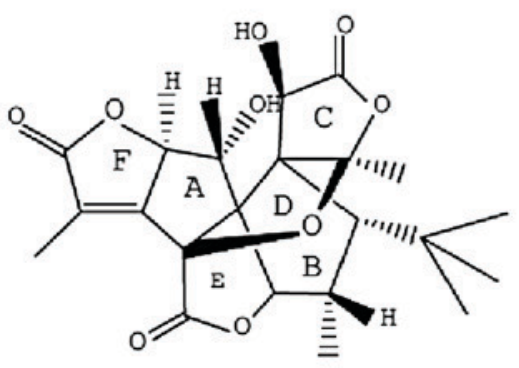

Ginkgolide K
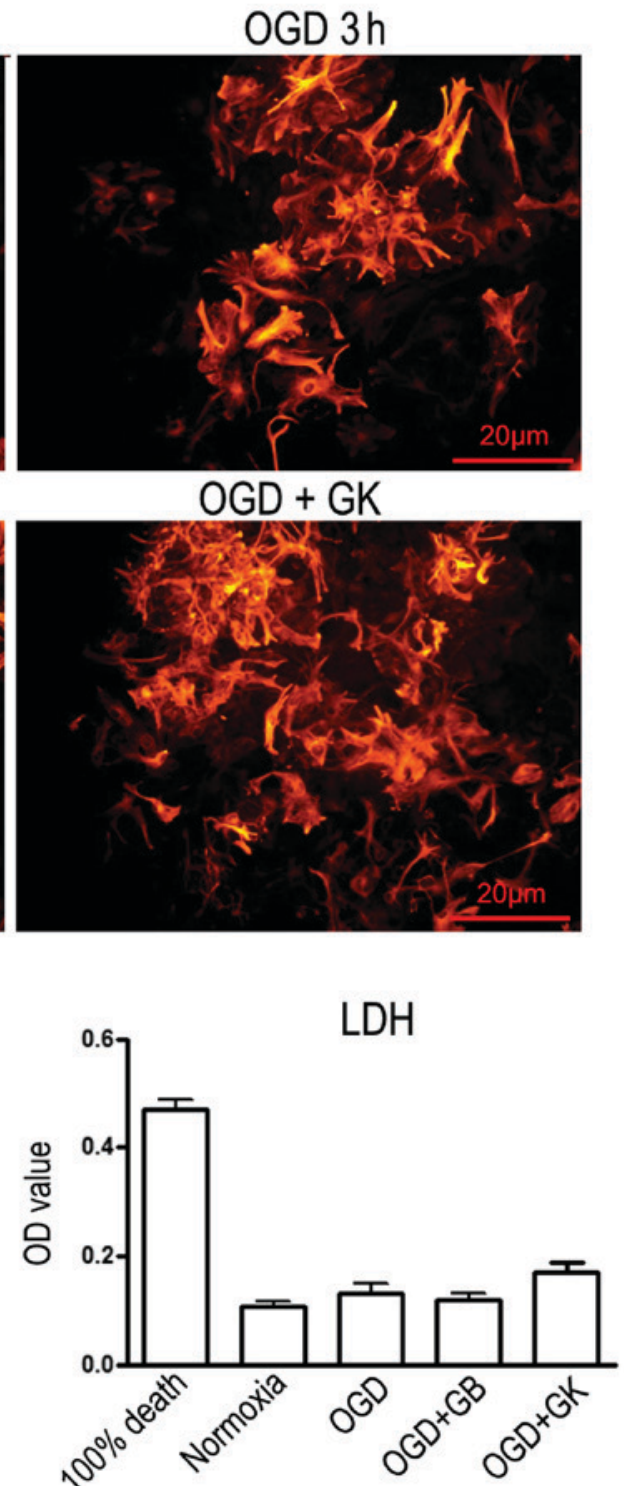

Figure 1. Structure and cytotoxicity of GB and GK. (A) The structure of GB and GK. (GB molecular formula: $\mathrm{C}_{20} \mathrm{H}_{24} \mathrm{O}_{10}$; and GK molecular formula: $\mathrm{C}_{20} \mathrm{H}_{22} \mathrm{O}_{9}$ ). (B) Immunostaining of GFAP in primary cultured astrocytes (scale bars, $20 \mu \mathrm{m}$ ). (C) The viability and level of cell death of astrocytes exposed to OGD or OGD $+\mathrm{GB} / \mathrm{GK}$. Cell viability was measured by MTT assay, and cell death was measured by LDH. Quantitative results are the mean \pm standard error of the mean, and analyzed from three independent experiments with similar results. " $\mathrm{P}<0.05$, as indicated. GB, ginkgolide B; GK, ginkgolide K; OGD, oxygen-glucose deprivation; GFAP, glial fibrillary acidic protein; LDH, lactate dehydrogenase; MTT, 3-(4,5-dimethylthazol-2-yl)-2,5-diphenyltetrazolium bromide.

by astrocytes was measured by ELISA. Supernatants from different cultures were collected and centrifuged at $2000 \mathrm{rpm}$ for $10 \mathrm{~min}$ to remove cell debris. The concentrations of IL-1 $\beta$, IL-6, IL-10, TNF- $\alpha$ and PAF in supernatants were measured using commercial immunoassay kits (IL-1 1 , IL-6, IL-10, and TNF- $\alpha$ from R\&D System and PAF; Cloud-Clone Corp., Houston, TX, USA) following the manufacturer's instructions and quantified by reference to standard curves. 
Western blot analysis. Protein from astrocytes was extracted on ice with RIPA buffer plus protease inhibitor and phosphatase inhibitor cocktail (both Thermo Fisher Scientific Inc.). Protein concentration was determined by BCA Protein Assay (Thermo Fisher Scientific Inc.). Protein extracts $(30 \mu \mathrm{g})$ were separated by SDS-PAGE and transferred onto nitrocellulose membranes (AmershamProtran 0.2 NC; GE Healthcare Life Sciences, Chicago, IL, USA). The membranes were then incubated with anti-p-NF-кB/p65 (Cell Signaling Technology, Inc., Danvers, MA, USA), anti-Nrf2, anti-heme oxygenase-1 (HO-1; both Abcam, Cambridge, MA, USA), anti-Nlrp3, anti-PI3K, anti-p-Akt (all Cell Signaling Technology, Inc.), anti-WNT-1 (Abgent Inc., San Diego, CA, USA), anti-Fzd1 (R\&D Systems, Inc., Minneapolis, MN, USA), anti- $\beta$-catenin (Cell Signaling Technology, Inc.), anti-BDNF (Abcam), anti-GDNF (Santa Cruz Biotechnology, Inc., Dallas, TX, USA), and anti- $\beta$-actin (Cell Signaling Technology, Inc.) antibodies overnight at $4^{\circ} \mathrm{C}$. Bands were visualized by HRP-conjugated secondary antibodies and chemiluminescence (ECL) kit (EMD Millipore, Billerica, MA, USA) under a ChemiDoc XRS+ system (Bio-Rad Laboratories, Inc., Hercules, CA, USA).

Immunocytochemistry. Cells were fixed for $20 \mathrm{~min}$ with $4 \%$ paraformaldehyde, blocked with Triton X-100 containing blocking buffer, and then incubated with antibodies against GFAP (Abcam) at $4^{\circ} \mathrm{C}$ overnight. After the cells were washed with PBS, the secondary antibody Alexa Fluor 555 goat anti-rabbit IgG (Thermo Fisher Scientific Inc.) was added. Immunoreactive cells were observed under fluorescence microscopy (BX60; Olympus Imaging America Inc.) by two investigators.

Statistical analysis. Data were presented as the mean \pm standard error of the mean. The raw data were analyzed by using one-way analysis of variance with Tukey's post hoc test, using GraphPad Prism 5.0 package (GraphPad Software, Inc, La Jolla, CA, USA). P<0.05 was considered to indicate a statistically significant difference.

\section{Results}

The structure and cytotoxicity of $G B$ and $G K$. Fig. 1A illustrates the structure of GB and GK. GB (molecular formula: $\mathrm{C} 20 \mathrm{H} 24 \mathrm{O} 10$ ) is one of the diterpenes that occurs naturally in the leaves of the Ginkgo biloba (25). GK (molecular formula: $\mathrm{C} 20 \mathrm{H} 22 \mathrm{O} 9$ ) is a derivative compound of GB. The morphology of astrocytes stained with GFAP was not abnormal after treatment with OGD, OGD+GB or OGD+GK; however, the number of GFAP-positive cells appeared to be reduced in astrocytes treated with OGD alone (Fig. 1B). The viability of astrocytes exposed to OGD for $3 \mathrm{~h}$ declined by $26.8 \%$ compared with the viability of astrocytes exposed to normoxic conditions (OD $0.77 \pm 0.05$ vs. $1.039 \pm 0.03$ ), while the viability of OGD astrocytes treated with GB and GK for $24 \mathrm{~h}$ was not significantly different from that of astrocytes exposed to OGD alone (Fig. 1C). The LDH release from OGD astrocytes with or without GB/GK treatment was similar to that from cells exposed to normoxia (Fig. 1C). The results demonstrate that the concentration of GB and GK used in this experimental

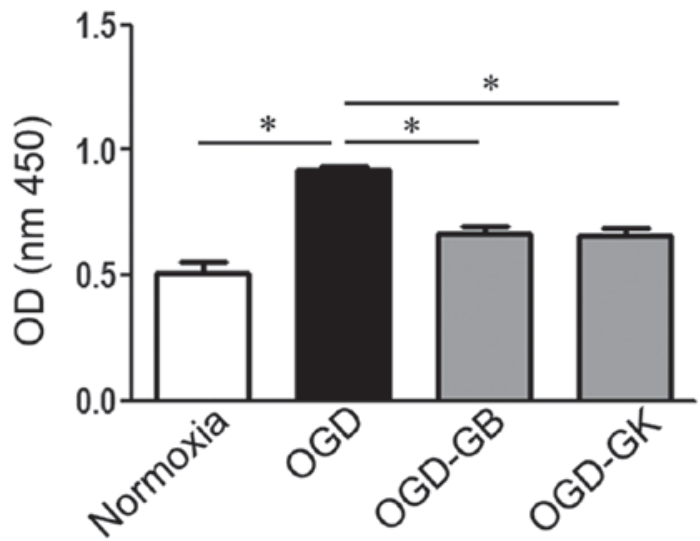

Figure 2. Effect of GB and GK on PAF inhibition in OGD astrocytes. Primary astrocytes were exposed to OGD for $3 \mathrm{~h}$. At the beginning of re-oxygenation, GB and GK (30 ug/ml, dissolved in DMSO) were added. The same volume of DMSO was added as a control. Following $24 \mathrm{~h}$, the supernatants were collected for the PAF assay. Quantitative results are the mean \pm standard error of the mean, and analyzed from three independent experiments with similar results. ${ }^{*} \mathrm{P}<0.05$, as indicated. $\mathrm{GB}$, ginkgolide $\mathrm{B}$; GK, ginkgolide $\mathrm{K}$; OGD, oxygen-glucose deprivation; PAF, platelet-activating factor; OD, optical density; DMSO, dimethyl sulfoxide.

did not influence the viability or death of cultured primary astrocytes.

Effect of $G B$ and GK on PAF inhibition in $O G D$ astrocytes. As shown in Fig. 2, PAF was xulated in cultured primary astrocytes treated with OGD for $3 \mathrm{~h}(\mathrm{P}<0.05)$. Both $\mathrm{GB}$ and $\mathrm{GK}$, as PAF antagonists, effectively inhibited the level of PAF compared with OGD treatment alone ( $\mathrm{P}<0.05$ for both).

Effect of $G B$ and $G K$ on the anti-inflammatory and antioxidant capacity of OGD astrocytes. In this study, both GB and GK inhibited the expression of $\mathrm{p}-\mathrm{NF}-\kappa \mathrm{B} / \mathrm{p} 65$ (Fig. 3A) $(\mathrm{P}<0.001$ for both), but neither changed N1rp3 expression in OGD astrocytes (Fig. 3A) (P>0.05). Compared to OGD astrocytes and GB-treated OGD astrocytes, OGD astrocytes treated with GK released less IL- 6 and TNF- $\alpha$ and produced more IL-10 (Fig. 3B) $(\mathrm{P}<0.001$ and $\mathrm{P}<0.01$ for IL-6, respectively, $\mathrm{P}<0.001$ for TNF- $\alpha$, and $\mathrm{P}<0.05$ for IL-10). These results show that both GB and GK suppressed the expression of $\mathrm{p}-\mathrm{NF}-\mathrm{\kappa B} / \mathrm{p} 65$ and that GK more effectively inhibited the production of inflammatory IL- 6 and TNF- $\alpha$ in OGD astrocytes. We measured antioxidative Nrf2 and HO-1 expression by western blot analysis. As shown in Fig. 4, although GB increased the expression of $\mathrm{Nrf} 2$, GK more efficiently induced the expression of Nrf2 (Fig. 4) ( $\mathrm{P}<0.05$ vs. OGD astrocytes treated with GB). Simultaneously, HO-1 expression was significantly elevated in OGD astrocytes treated with GK (Fig. 4) $(\mathrm{P}<0.05)$. These results indicate that $\mathrm{GK}$ efficiently induced the expression of antioxidative Nrf2 and HO-1 in OGD astrocytes.

We measured antioxidative Nrf 2 and HO-1 expression by Western blot. As shown in Fig. 4, although GB increased the expression of $\mathrm{Nrf} 2$, GK more efficiently induced the expression of Nrf2 (Fig. 4) (P<0.05 vs. OGD astrocytes treated with GB). Simultaneously, HO-1 expression was significantly elevated in OGD astrocytes treated with GK (Fig. 4) $(\mathrm{P}<0.05)$. These results indicate that GK efficiently induced the expression of antioxidative Nrf2 and HO-1 in OGD astrocytes. 
A
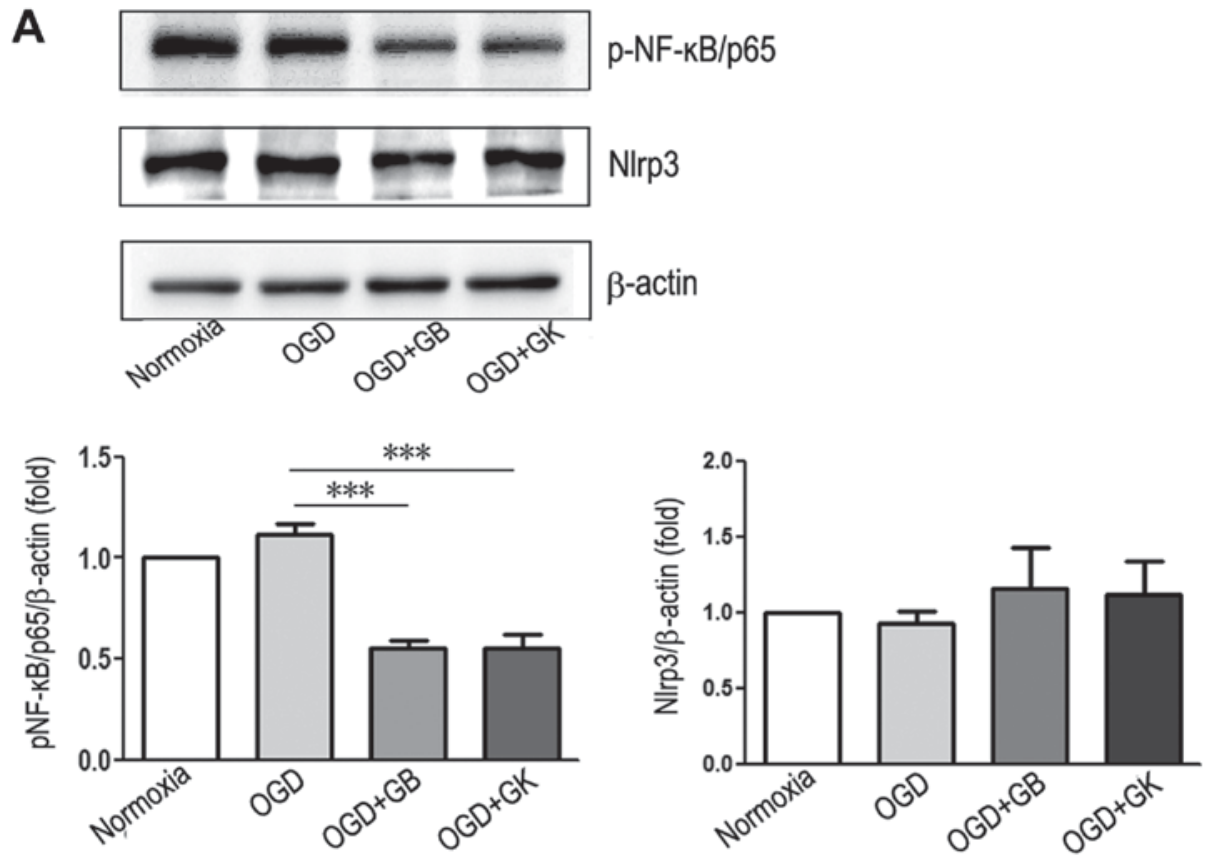

B IL-1 $\beta$

IL-6
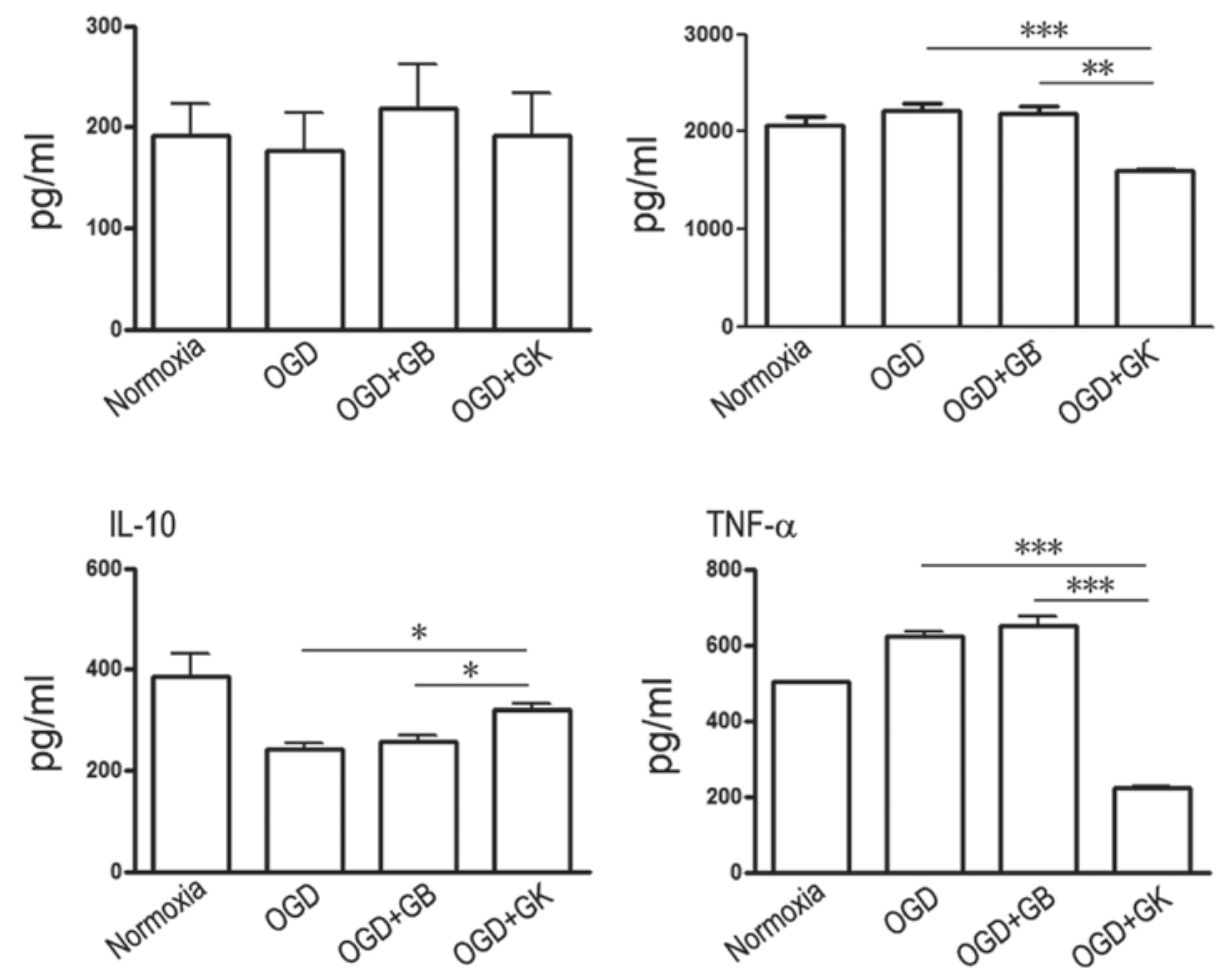

Figure 3. Anti-inflammatory effects of GB and GK in OGD astrocytes. Primary astrocytes were exposed to OGD for 3 h. At the beginning of re-oxygenation, GB and GK (30 $\mu \mathrm{g} / \mathrm{ml}$, dissolved in DMSO) were added. The same volume of DMSO was added as a control. Following $24 \mathrm{~h}$, the supernatants were collected for ELISA assay, and the cells were collected for western blotting. (A) The protein expression of p-NF- $\kappa \mathrm{B} / \mathrm{p} 65$ and Nlrp3 by western blot, and (B) the concentrations of IL-1 $\beta$, IL-6, IL-10 and TNF- $\alpha$ by ELISA. Semi-quantitative results are presented as the mean \pm standard error of the mean, and analyzed from three independent experiments with similar results. ${ }^{*} \mathrm{P}<0.05,{ }^{* *} \mathrm{P}<0.01$ and ${ }^{* * *} \mathrm{P}<0.001$, as indicated. GB, ginkgolide B; GK, ginkgolide K; OGD, oxygen-glucose deprivation; p-, phosphorylated; NF- $\kappa$ B, nuclear factor- $\kappa \mathrm{B}$; Nlrp3, NLR family pyrin domain containing 3; IL-, interleukin; TNF- $\alpha$, tumor necrosis factor- $\alpha$; DMSO, dimethyl sulfoxide.

Effect of GB and GK on PI3K/Akt pathway of OGD-astrocytes. Phosphorylated PI3K/Akt pathway serves an anti-inflammatory role through suppressing the phosphorylation of

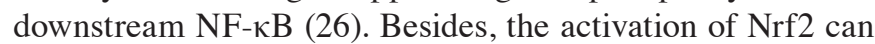
be modulated via PI3K/Akt pathway (27). We compared the role of GB and GK on PI3K/Akt pathway of OGD-astrocytes. As shown in Fig. 5, after OGD-astrocytes cells were treated with GB, the expression of PI3K and p-Akt was inhibited compared with OGD-astrocytes alone (for PI3K P $<0.05$, and for $\mathrm{p}-\mathrm{AKT} \mathrm{P}=0.084$ ), although the latter did not reach statistical 


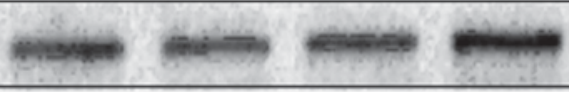

$\mathrm{HO}-1$
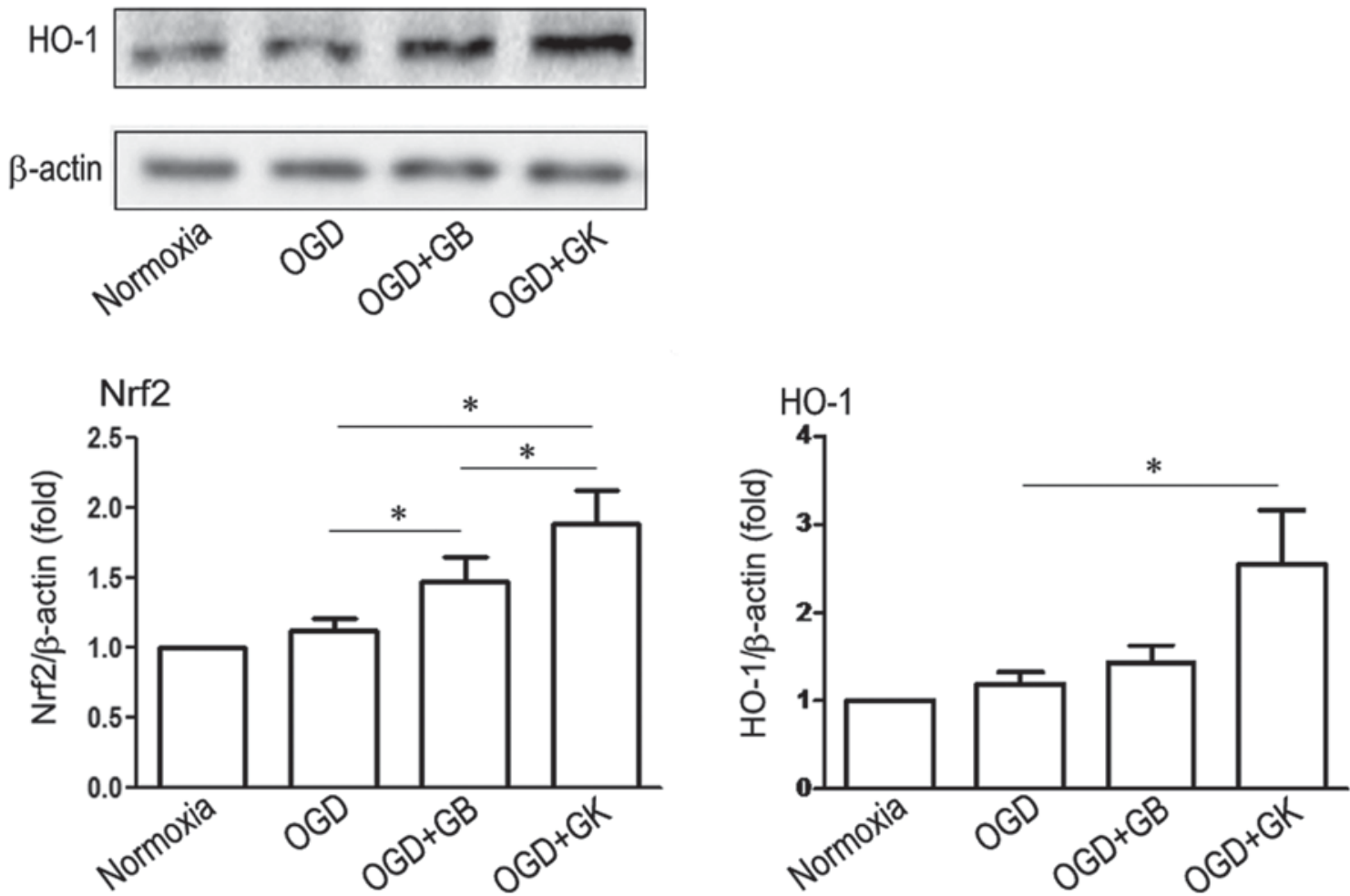

Figure 4. Antioxidative effects of GB and GK in OGD astrocytes. Primary astrocytes were exposed to OGD for $3 \mathrm{~h}$. At the beginning of re-oxygenation, GB and GK (30 $\mu \mathrm{g} / \mathrm{ml}$, dissolved in DMSO) were added. The same volume of DMSO was added as a control. Following $24 \mathrm{~h}$, the cells were collected to measure the expression of Nrf2 and HO-1 by western blotting. Semi-quantitative results are the mean \pm standard error of the mean, and analyzed from three independent experiments with similar results. " $\mathrm{P}<0.05$, as indicated. GB, ginkgolide B; GK, ginkgolide K; OGD, oxygen-glucose deprivation; Nrf2, nuclear factor-erythroid 2-related factor 2; DMSO, dimethyl sulfoxide; HO-1, heme oxygenase-1.

significance. However, the treatment of GK on OGD-astrocytes showed higher expression of PI3K and p-AKT compared with GB (Fig. 5) ( $\mathrm{P}<0.05$, respectively).

Effect of GB and GK on the WNT-1-Fzd1- $\beta$-catenin pathway in $O G D$ astrocytes. The secreted Wnt1 ligand binds to its corresponding receptor, Fzd1, which activates the downstream WNT pathway that regulates neuronal proliferation and differentiation (28) and promotes angiogenesis (29). Compared with OGD treatment alone and OGD treatment with GB, GK treatment induced the expression of WNT-1 (Fig. 6) $(\mathrm{P}<0.05$ and $\mathrm{P}<0.01$, respectively), but did not enhance the expression of either Fzd1 or $\beta$-catenin in OGD astrocytes (Fig. 6).

The PI3K/Akt pathway mediates BDNF effects (30), while BDNF promotes the growth of neurons in vitro through crosstalk with the WNT//3-catenin pathway (31). As shown in Fig. 7, GK treatment induced the expression of BDNF (Fig. 6) $(\mathrm{P}<0.05$, respectively) but not GDNF compared with OGD treatment alone and OGD treatment with GB.

\section{Discussion}

Astrocytes are the most numerous non-neuronal cell type in the brain, stimulating neurite outgrowth and promoting neuronal survival and regeneration through bi-directional communication between astrocytes and neurons in the brain. The recent discovery that astrocytes can differentiate into neurons under some microenvironments has dramatically expanded our knowledge of the regulation of astrocytes to neurons (32). In addition to providing support to neurons, astrocytes can also secrete a series of pro-inflammatory cytokines that modify the microenvironment $(33,34)$, which is crucial for the pathological processes of the brain (35). In the present study, we found that both GB and GK inhibited the expression of inflammatory $\mathrm{p}-\mathrm{NF}-\kappa \mathrm{B} / \mathrm{p} 65$, and GK upregulated the expression of antioxidative Nrf2 and HO-1 in OGD astrocytes, which could have a neuroprotective effect through anti-inflammatory and anti-oxidative actions. Interestingly, our study found that compared with GB, GK induced astrocytic production of IL-10 and decreased IL- 6 and TNF- $\alpha$ expression. These results demonstrated that GK shows stronger anti-inflammatory and antioxidant effects on OGD astrocytes.

Nrf2 signaling in astrocytes has been suggested as an important therapeutic target for brain disorders (36). The activation of the Nrf2/HO-1 axis plays a pivotal role in coordinating the antioxidant response and maintaining redox homeostasis (27). The depletion of Nrf2 induced the activation of NF- $\mathrm{kB}$ and the expression of TNF- $\alpha$, IL-1 $\beta$, IL- 6 and MMP9 resulting in more cell death in astrocytes after scratch injury, suggesting that Nrf2 may be an important target for anti-inflammation $(37,38)$. The activation of NF-KB induced by LPS was attenuated by various Nrf2 activators, such as sulforaphane and curcumin (39), 

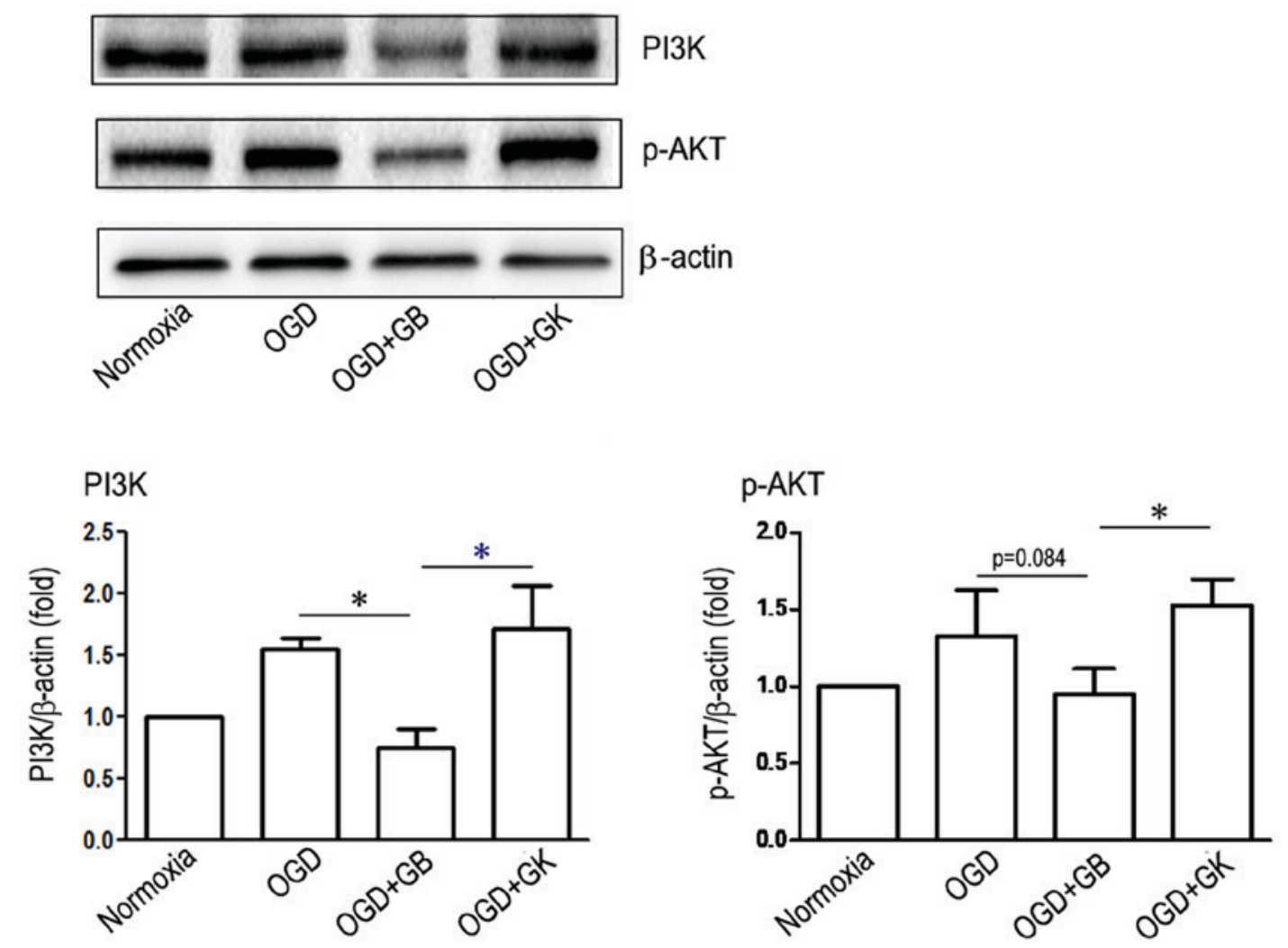

Figure 5. Effect of GB and GK on the PI3K-AKT signaling pathway in OGD astrocytes. Primary astrocytes were exposed to OGD for 3 h. At the beginning of re-oxygenation, GB and GK ( $30 \mu \mathrm{g} / \mathrm{ml}$, dissolved in DMSO) were added. The same volume of DMSO was added as a control. Following $24 \mathrm{~h}$, the cells were collected to measure the expression of PI3K and p-AKT by western blotting. Semi-quantitative results are the presented as the mean \pm standard error of the mean, and analyzed from three independent experiments with similar results. * $\mathrm{P}<0.05$, as indicated. GB, ginkgolide B; GK, ginkgolide K; OGD, oxygen-glucose deprivation; PI3K, phosphoinositide 3-kinase; AKT, protein kinase B; p-, phosphorylated; DMSO, dimethyl sulfoxide.

indicating that depletion of Nrf2 induces augmentation of $\mathrm{NF}-\kappa \mathrm{B}$ activity and the inflammatory response in the lung, brain, and intestine (40). In this study, GK treatment inhibited the expression of $\mathrm{p}-\mathrm{NF}-\kappa \mathrm{B} / \mathrm{p} 65$ and upregulated the Nrf2 pathway, indicating potential complicated crosstalk between $\mathrm{NF}-\kappa \mathrm{B}$ and $\mathrm{Nrf} 2$, which may contribute to the improvement in the inflammatory microenvironment of the brain and promote neuroprotection and nerve regeneration. In this study, the inhibition of NF- $\mathrm{NB}$ and TNF- $\alpha$ in OGD astrocytes treated with GK might be related to the increased expression of IL-10 (41-43). Additionally, a series of studies have demonstrated that the activation and nuclear translocation of $\mathrm{Nrf} 2$ and the expression of various antioxidant enzymes can be mediated via the PI3K/Akt pathway $(44,45)$.

PAF is a pleiotropic endogenous phospholipid that mediates a diverse range of physiologic and pathologic processes. PAF is produced by different cells, including mast cells, basophils, neutrophils, eosinophils, fibroblasts, platelets, endothelial cells, and even cardiac muscle cells (46). PAF is also synthesized in cultured neurons following stimulation with neurotransmitters such as NMDA and glutamic acid (47). However, microglia has a chemotactic response to PAF, revealing that PAF is one of the key mediators in neuron-microglia interactions (47). Additionally, endothelial cells were found to produce PAF after stimulation by hypoxia or inflammatory mediators (48). In this study, PAF was also produced by astrocytes and was induced by OGD. Both GB and GK inhibited the release of PAF from OGD astrocytes. Because the PAF receptor is also expressed on neurons (49), PAF released from OGD astrocytes also induces neuronal toxicity via a paracrine pathway. Reducing PAF neurotoxic effects in the CNS with open new therapeutic targets.

PAF has been reported to cause apoptosis in enterocytes by inhibiting the PI3K/Akt signaling pathway (50). However, there is no reason to believe that the GK-induced upregulation of PI3K/Akt expression is related to PAF inhibition because GB also inhibited PAF but did not increase the expression of PI3K/Akt. There is growing evidence to indicate crosstalk between the Nrf2 and PI3K/Akt pathways in response to oxidative insults $(51,52)$. Previous research has demonstrated that the PI3K/Akt pathway plays a critical role in modulating Nrf2/HO-1 protein expression as an upstream signaling molecule (53). In our present study, a difference in PI3K/Akt expression was observed between OGD astrocytes treated with GB and GK, and this difference was possibly mediated by different modes of action.

Astrocytes have been suggested to maintain neuronal activity and modulate neuronal networks. Thus, their structural integrity and sustained function are essential for neuronal viability (54). The Wnt/ $\beta$-catenin signaling pathway has been intensely studied as a critical regulator of cell proliferation and cell fate during development, including neural development $(55,56)$. Recently, the Wnt1-regulated frizzled-1/Fzd/ $\beta$-catenin signaling pathway was demonstrated to act as a candidate regulatory circuit by controlling dopaminergic neuron-astrocyte crosstalk (57) or protecting cells from $\mathrm{A} \beta$-oligomers toxicity (58). Most interestingly, we found that 

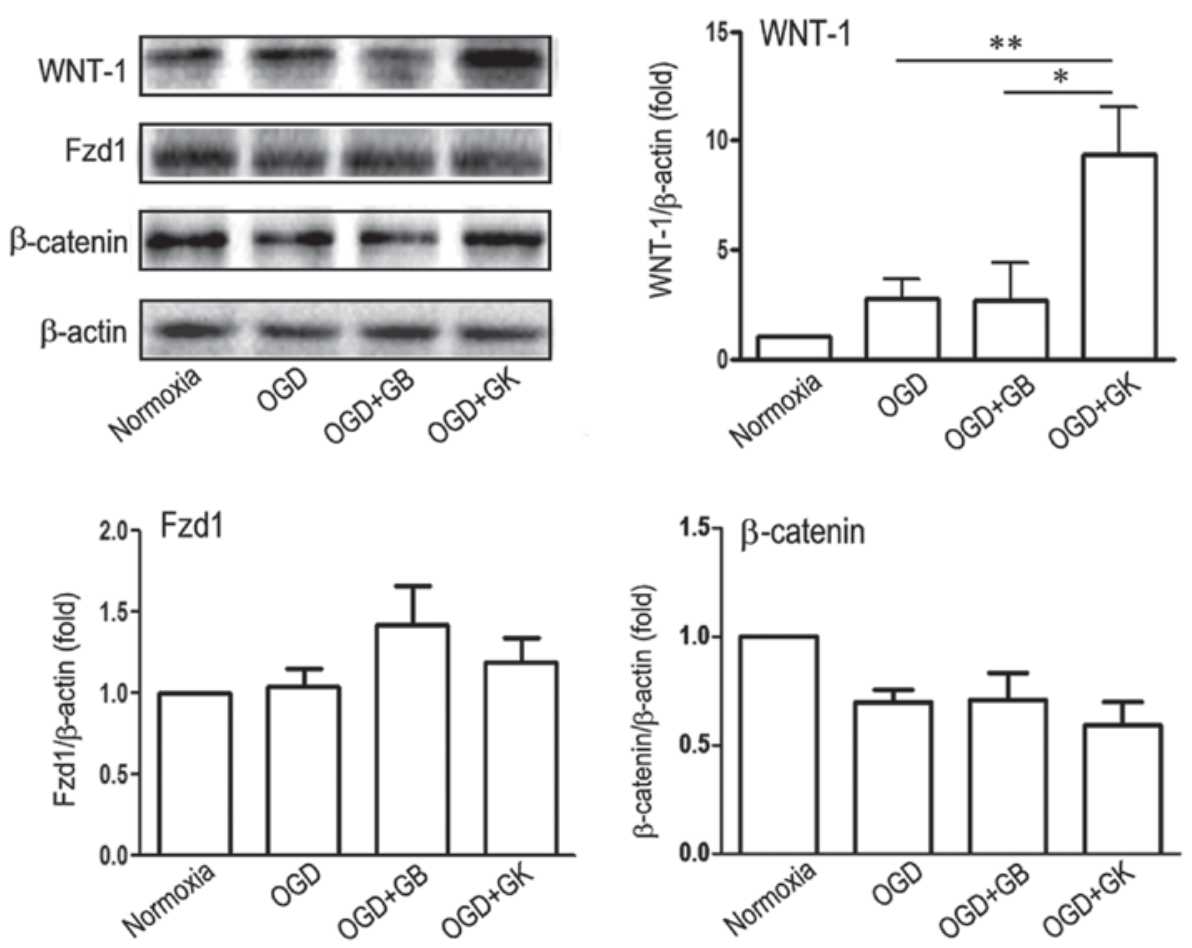

Figure 6. Effect of GB and GK on the WNT-1/Fzd1/ $\beta$-catenin signaling pathway in OGD astrocytes. Primary astrocytes were exposed to OGD for $3 \mathrm{~h}$. At the beginning of re-oxygenation, GB and GK $(30 \mu \mathrm{g} / \mathrm{ml}$, dissolved in DMSO) were added. The same volume of DMSO was added as a control. Following $24 \mathrm{~h}$, the cells were collected to measure the expression of WNT-1, Fzd1 and $\beta$-catenin by western blotting. Semi-quantitative results are the presented as the mean \pm standard error of the mean, and analyzed from three independent experiments with similar results. ${ }^{*} \mathrm{P}<0.05$ and ${ }^{* *} \mathrm{P}<0.01$, as indicated. GB, ginkgolide B; GK, ginkgolide K; OGD, oxygen-glucose deprivation; WNT-1, Wnt family member 1; Fzd1, frizzled class receptor 1; DMSO, dimethyl sulfoxide.
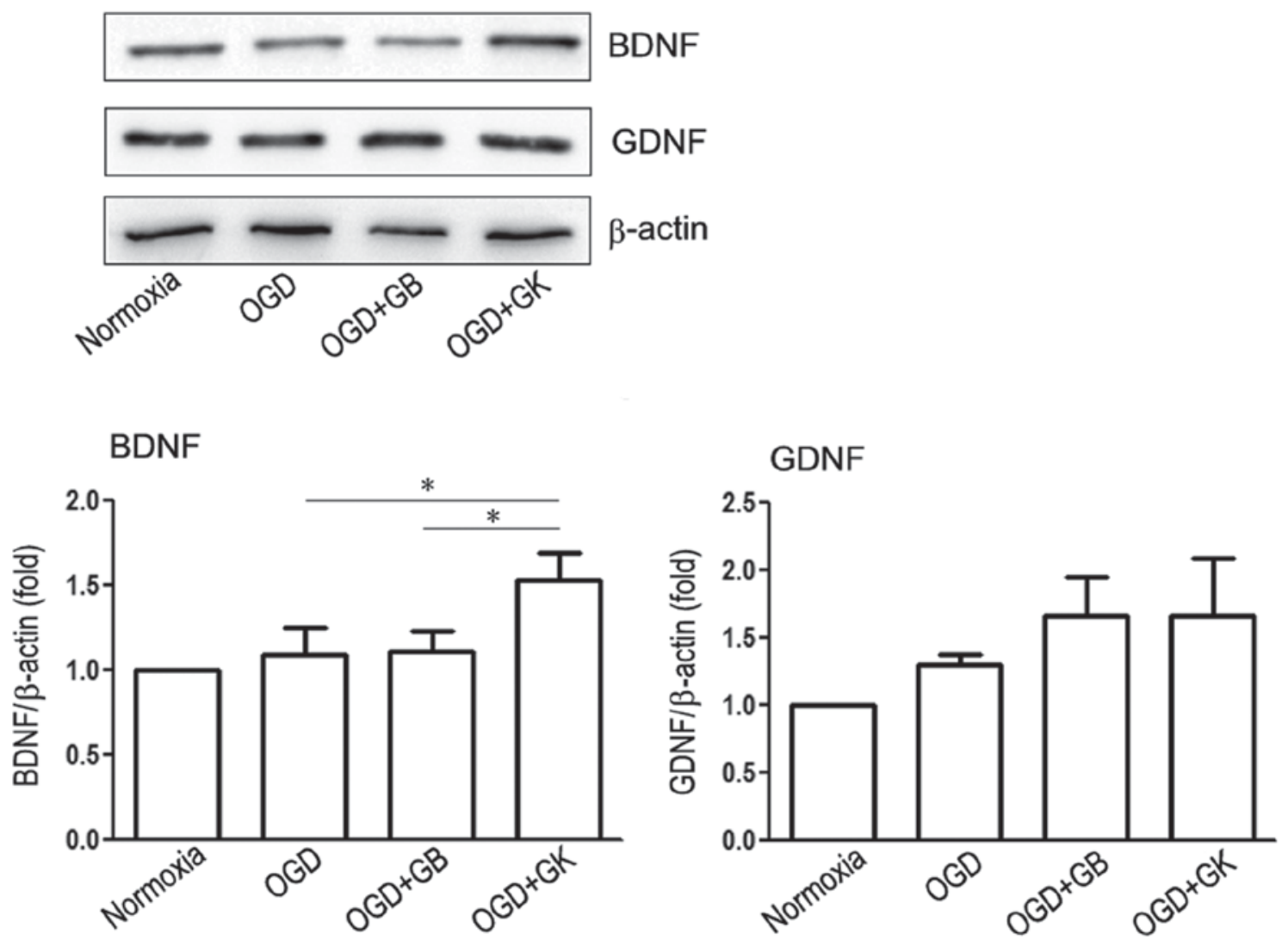

Figure 7. Effect of GB and GK on neurotrophic factors BDNF and GDNF in OGD astrocytes. Primary astrocytes were exposed to OGD for $3 \mathrm{~h}$. At the beginning of re-oxygenation, GB and GK ( $30 \mu \mathrm{g} / \mathrm{ml}$, dissolved in DMSO) were added. The same volume of DMSO was added as a control. Following $24 \mathrm{~h}$, the cells were collected to measure the expression of BDNF and GDNF by western blotting. Semi-quantitative results are presented as the mean \pm standard error of the mean, and analyzed from three independent experiments with similar results. "P<0.05, as indicated. GB, ginkgolide B; GK, ginkgolide K; OGD, oxygen-glucose deprivation; BDNF, brain derived neurotrophic factor; GDNF, glial cell derived neurotrophic factor; DMSO, dimethyl sulfoxide. 
compared to GB, GK treatment obviously induced the upregulation in WNT1 expression but did not influence the expression of Fzd or $\beta$-catenin in OGD astrocytes. Secreted WNT1 molecules have been shown to be important not only for healthy brain development but also for neurogenesis $(59,60)$. Our results are consistent with the current opinion that astrocytes in the adult brain, in addition to providing structural support for neurons, also perform numerous functions that include forming neuronal-glial-vascular units. Here, our results suggest that GK treatment induced the expression of WNT1 in OGD astrocytes.

Since knocking down WNT1 in midbrain astrocytes abolished DA neuroprotection, defining the Wnt1/Fzd-1/ $\beta$-catenin pathway as a novel astrocyte-neuron signaling system required for survival and protection of adult midbrain DA neurons may be necessary (57). BDNF is postulated to be a direct target of the WNT pathway in glia. A previous study showed that the WNT signaling pathway might directly induce BDNF expression in Muller glia of the retina (61). In fact, BDNF and GDNF, as secretory cytokines, should be able to determine the content in the supernatant, but unlike other cytokines, the measurement of BDNF and GDNF content in the supernatant is relatively complex and unstable by ELISA method. In this study, we detected protein level in cell extracts by Western blot. Our data do not exclude the possibility that indirect regulation of BDNF expression by WNT signaling may occur, possibly via WNT-dependent induction (62). In conclusion, this is the first comparative study between the effects of GB and GK on OGD astrocytes, demonstrating that these compounds have some different biological effects. PAF expression was elevated in OGD astrocytes and inhibited by both GB and GK treatment. Although both GB and GK inhibited the expression of $\mathrm{p}-\mathrm{NF}-\mathrm{\kappa B} / \mathrm{p} 65$, GK showed stronger anti-inflammatory and antioxidant effects in OGD astrocytes. Compared to GB treatment, GK treatment resulted in a higher expression of $\mathrm{PI} 3 \mathrm{~K}$ and $\mathrm{p}$-Akt and induced upregulation of WNT1 and BDNF expression, indicating that GK, as a natural plant compound, may have more attractive prospects for clinical application in the treatment of neurological disorders than GB.

\section{Acknowledgements}

Not applicable.

\section{Funding}

The present study was supported by grants from the National Natural Science Foundation of China (grant no. 81371414), and National Major Scientific and Technological Special Project for Significant New Drugs Development (grant no. 2013ZX09402203).

\section{Availability of data and materials}

The datasets used and/or analyzed during the current study are available from the corresponding author on reasonable request.

\section{Authors' contributions}

LC, WX and B-GX designed the study. W-BY, Y-YZ and B-GX performed the experiments. W-BY and B-GX wrote the manuscript. All authors read and approved the final manuscript.

\section{Ethics approval and consent to participate}

The present study was approved by the Ethics Committee of Fudan University, based on the recommendations established in the Guide for the National Science Council of the Republic of China (no. 20150572A259).

\section{Patient consent for publication}

Not applicable.

\section{Competing interests}

The authors declare that they have no competing interests.

\section{References}

1. Seth P and Koul N: Astrocyte, the star avatar: Redefined. J Biosci 33: 405-421, 2008.

2. Travis J: Glia: The brain's other cells. Science 266: 970-972, 1994.

3. Hahn J, Wang X and Margeta M: Astrocytes increase the activity of synaptic GluN2B NMDA receptors. Front Cell Neurosci 9: 117,2015

4. Singh SK, Stogsdill JA, Pulimood NS, Dingsdale H, Kim YH, Pilaz LJ, Kim IH, Manhaes AC, Rodrigues WS Jr, Pamukcu A, et al: Astrocytes assemble thalamocortical synapses by bridging NRX1 $\alpha$ and NL1 via hevin. Cell 164: 183-196, 2016.

5. Filosa JA, Morrison HW, Iddings JA, Du W and Kim KJ: Beyond neurovascular coupling, role of astrocytes in the regulation of vascular tone. Neuroscience 323: 96-109, 2016.

6. Xu L, Dan M, Shao A, Cheng X, Zhang C, Yokel RA, Takemura T, Hanagata N, Niwa M and Watanabe D: Silver nanoparticles induce tight junction disruption and astrocyte neurotoxicity in a rat blood-brain barrier primary triple coculture model. Int $\mathrm{J}$ Nanomedicine 10: 6105-6118, 2015.

7. Giaume $\mathrm{C}$ and Oliet $\mathrm{S}$ : Introduction to the special issue: Dynamic and metabolic interactions between astrocytes and neurons. Neuroscience 323: 1-2, 2016.

8. Tewari SG, Gottipati MK and Parpura V: Mathematical modeling in neuroscience: Neuronal activity and its modulation by astrocytes. Front Integr Neurosci 10: 3, 2016.

9. Capani F, Quarracino C, Caccuri R and Sica RE: Astrocytes as the main players in primary degenerative disorders of the human central nervous system. Front Aging Neurosci 8: 45, 2016.

10. Liu Z and Chopp M: Astrocytes, therapeutic targets for neuroprotection and neurorestoration in ischemic stroke. Prog Neurobiol 144: 103-120, 2016.

11. Verkhratsky A, Steardo L, Parpura V and Montana V: Translational potential of astrocytes in brain disorders. Prog Neurobiol 144: 188-205, 2016.

12. Ahlemeyer B and Krieglstein J: Pharmacological studies supporting the therapeutic use of ginkgo biloba extract for Alzheimer's disease. Pharmacopsychiatry 1 (Suppl 36): S8-S14, 2003.

13. Luo Y, Smith JV, Paramasivam V, Burdick A, Curry KJ, Buford JP, Khan I, Netzer WJ, Xu H and Butko P: Inhibition of amyloid-beta aggregation and caspase-3 activation by the ginkgo biloba extract EGb761. Proc Natl Acad Sci USA 99: 12197-12202, 2002.

14. Curtis-Prior P, Vere D and Fray P: Therapeutic value of ginkgo biloba in reducing symptoms of decline in mental function. J Pharm Pharmacol 51: 535-541, 1999.

15. Chung KF, Dent G, McCusker M, Guinot P, Page CP and Barnes PJ: Effect of a ginkgolide mixture (BN 52063) in antagonising skin and platelet responses to platelet activating factor in man. Lancet 1: 248-251, 1987.

16. Pei HX, Hua R, Guan CX and Fang X: Ginkgolide B reduces the degradation of membrane phospholipids to prevent ischemia/reperfusion myocardial injury in rats. Pharmacology 96: 233-239, 2015.

17. Shu ZM, Shu XD, Li HQ, Sun Y, Shan H, Sun XY, Du RH, Lu M, Xiao M, Ding JH and Hu G: Ginkgolide B protects against ischemic stroke via modulating microglia polarization in mice. CNS Neurosci Ther 22: 729-739, 2016. 
18. Zheng JL, Li BS, Cao XC, Zhuo WK and Zhang G: Alleviation of spinal cord injury by ginkgolide B via the inhibition of STAT1 expression. Genet Mol Res 15: 4248, 2016.

19. Zhou T, You WT, Ma ZC, Liang QD, Tan HL, Xiao CR, Tang XL, Zhang BL, Wang YG and Gao Y: Ginkgolide B protects human umbilical vein endothelial cells against xenobiotic injuries via PXR activation. Acta Pharmacol Sin 37: 177-186, 2016.

20. Chi CL, Shen DF, Wang PJ, Li HL and Zhang L: Effect of ginkgolide $\mathrm{B}$ on brain metabolism and tissue oxygenation in severe haemorrhagic stroke. Int J Clin Exp Med 8: 3522-3529, 2015.

21. Ma S, Liu H, Jiao H, Wang L, Chen L, Liang J, Zhao M and Zhang X: Neuroprotective effect of ginkgolide $\mathrm{K}$ on glutamate-induced cytotoxicity in PC 12 cells via inhibition of ROS generation and $\mathrm{Ca}(2+)$ influx. Neurotoxicology 33: 59-69, 2012.

22. Ma S, Liu X, Xun Q and Zhang X: Neuroprotective effect of Ginkgolide K against $\mathrm{H} 2 \mathrm{O} 2$-induced $\mathrm{PC} 12$ cell cytotoxicity by ameliorating mitochondrial dysfunction and oxidative stress Biol Pharm Bull 37: 217-225, 2014.

23. Wang S, Wang Z, Fan Q, Guo J, Galli G, Du G, Wang X and Xiao W: Ginkgolide K protects the heart against endoplasmic reticulum stress injury by activating the inositol-requiring enzyme $1 \alpha / \mathrm{X}$ box-binding protein-1 pathway. $\mathrm{Br} \mathrm{J}$ Pharmacol 173: 2402-2418, 2016.

24. Ma S, Yin H, Chen L, Liu H, Zhao $M$ and Zhang $X$ Neuroprotective effect of ginkgolide $\mathrm{K}$ against acute ischemic stroke on middle cerebral ischemia occlusion in rats. J Nat Med 66: 25-31, 2012

25. Maclennan KM, Darlington CL and Smith PF: The CNS effects of ginkgo biloba extracts and ginkgolide B. Prog Neurobiol 67: 235-257, 2002.

26. Rao CY, Fu LY, Hu CL, Chen DX, Gan T, Wang YC and Zhao XY: H2S mitigates severe acute pancreatitis through the $\mathrm{PI} 3 \mathrm{~K} / \mathrm{AKT}-\mathrm{NF}-\kappa \mathrm{B}$ pathway in vivo. World J Gastroenterol 21 4555-4563, 2015.

27. de Oliveira MR, Ferreira GC and Schuck PF: Protective effect of carnosic acid against paraquat-induced redox impairment and mitochondrial dysfunction in SH-SY5Y cells: Role for PI3K/Akt/Nrf2 pathway. Toxicol In Vitro 32: 41-54, 2016.

28. Tang K, Yang J, Gao X, Wang C, Liu L, Kitani H, Atsumi T and Jing N: Wnt-1 promotes neuronal differentiation and inhibits gliogenesis in P19 cells. Biochem Biophys Res Commun 293: $167-173,2002$

29. Masckauchan TN, Shawbe CJ, Funahashi Y, Li CM and Kitajewski J: Wnt/beta-catenin signaling induces proliferation, survival and interleukin-8 in human endothelial cells. Angiogenesis 8: 43-51, 2005.

30. Liu M, Kay JC, Shen S and Qiao LY: Endogenous BDNF augments NMDA receptor phosphorylation in the spinal cord via PLCgamma, PKC, and PI3K/Akt pathways during colitis. J Neuroinflammation 12: 151, 2015.

31. Yang JW, Ru J, Ma W, Gao Y, Liang Z, Liu J, Guo JH and Li LY: BDNF promotes the growth of human neurons through crosstalk with the Wnt/ $\beta$-catenin signaling pathway via GSK-3 $\beta$. Neuropeptides 54: 35-46, 2015.

32. Magnusson JP, Goritz C, Tatarishvili J, Dias DO, Smith EM, Lindvall $\mathrm{O}$, Kokaia $\mathrm{Z}$ and Frisén J: A latent neurogenic program in astrocytes regulated by Notch signaling in the mouse. Science 346: 237-241, 2014.

33. Rossi DJ, Brady JD and Mohr C: Astrocyte metabolism and signaling during brain ischemia. Nat Neurosci 10: 1377-1386, 2007.

34. Choudhury GR and Ding S: Reactive astrocytes and therapeutic potential in focal ischemic stroke. Neurobiol Dis 85: 234-244, 2016.

35. Amantea D, Micieli G, Tassorelli C, Cuartero MI, Ballesteros I, Certo M, Moro MA, Lizasoain I and Bagetta G: Rational modulation of the innate immune system for neuroprotection in ischemic stroke. Front Neurosci 9: 147, 2015.

36. Vargas MR and Johnson JA: The Nrf2-ARE cytoprotective pathway in astrocytes. Expert Rev Mol Med 11: e17, 2009.

37. Cao X, Xiao H, Zhang Y, Zou L, Chu Y and Chu X: 1, 5-Dicaffeoylquinic acid-mediated glutathione synthesis through activation of Nrf2 protects against OGD/reperfusion-induced oxidative stress in astrocytes. Brain Res 1347: $142-148,2010$

38. Pan H, Wang H, Zhu L, Mao L, Qiao L and Su X: Depletion of Nrf2 enhances inflammation induced by oxyhemoglobin in cultured mice astrocytes. Neurochem Res 36: 2434-2441, 2011.
39. Jeong WS, Kim IW, Hu R and Kong AN: Modulatory properties of various natural chemopreventive agents on the activation of NF-kappaB signaling pathway. Pharm Res 21: 661-670, 2004

40. Jin W, Wang H, Yan W, Zhu L, Hu Z, Ding Y and Tang K: Role of Nrf2 in protection against traumatic brain injury in mice. J Neurotrauma 26: 131-139, 2009.

41. Sondergaard JN, Poghosyan S, Hontelez S, Louche P, Looman MW, Ansems M and Adema GJ: DC-SCRIPT regulates IL-10 production in human dendritic cells by modulating NF-кBp65 activation. J Immunol 195: 1498-1505, 2015.

42. Hovsepian E, Penas F, Siffo S, Mirkin GA and Goren NB: IL-10 inhibits the NF- $\kappa \mathrm{B}$ and ERK/MAPK-mediated production of pro-inflammatory mediators by up-regulation of SOCS-3 in Trypanosoma cruzi-infected cardiomyocytes. PLoS One 8: e79445, 2013.

43. Wang Y, Fan L, Meng X, Jiang F, Chen Q, Zhang Z and Yan H: Transplantation of IL-10-transfected endothelial progenitor cells improves retinal vascular repair via suppressing inflammation in diabetic rats. Graefes Arch Clin Exp Ophthalmol 254: 1957-1965, 2016

44. Jang HJ, Hong EM, Kim M, Kim JH, Jang J, Park SW, Byun HW, Koh DH, Choi MH, Kae SH and Lee J: Simvastatin induces heme oxygenase-1 via NF-E2-related factor 2 (Nrf2) activation through ERK and PI3K/Akt pathway in colon cancer. Oncotarget 7: 46219-46229, 2016.

45. Xu L, He S, Yin P, Li D, Mei C, Yu X, Shi Y, Jiang L and Liu F: Punicalagin induces Nrf2 translocation and HO-1 expression via PI3K/Akt, protecting rat intestinal epithelial cells from oxidative stress. Int J Hyperthermia 32: 465-473, 2016.

46. Palgan K and Bartuzi Z: Platelet activating factor in allergies. Int J Immunopathol Pharmacol 28: 584-589, 2015.

47. Aihara M, Ishii S, Kume K and Shimizu T: Interaction between neurone and microglia mediated by platelet-activating factor. Genes Cells 5: 397-406, 2000.

48. Montrucchio G, Alloatti G and Camussi G: Role of platelet-activating factor in cardiovascular pathophysiology. Physiol Rev 80: 1669-1699, 2000

49. Li Z, Shu Q, Li L, Ge M and Zhang Y: Sequential expression of cyclooxygenase-2, glutamate receptor-2, and platelet activating factor receptor in rat hippocampal neurons after fluid percussion injury. Neural Regen Res 9: 978-985, 2014.

50. Lu J, Caplan MS, Li D and Jilling T: Polyunsaturated fatty acids block platelet-activating factor-induced phosphatidylinositol 3 kinase/Akt-mediated apoptosis in intestinal epithelial cells. Am J Physiol Gastrointest Liver Physiol 294: G1181-G1190, 2008.

51. Nakaso K, Yano H, Fukuhara Y, Takeshima T, Wada-Isoe K and Nakashima K: PI3K is a key molecule in the Nrf2-mediated regulation of antioxidative proteins by hemin in human neuroblastoma cells. FEBS Lett 546: 181-184, 2003.

52. Hwang YP and Jeong HG: Ginsenoside Rb1 protects against 6-hydroxydopamine-induced oxidative stress by increasing heme oxygenase-1 expression through an estrogen receptor-related PI3K/Akt/Nrf2-dependent pathway in human dopaminergic cells. Toxicol Appl Pharmacol 242: 18-28, 2010.

53. Xu X, Li H, Hou X, Li D, He S, Wan C, Yin P, Liu M, Liu F and $\mathrm{Xu} \mathrm{J}$ : Punicalagin induces Nrf2/HO-1 expression via upregulation of PI3K/AKT pathway and inhibits LPS-induced oxidative stress in RAW264.7 macrophages. Mediators Inflamm 2015: $380218,2015$.

54. Pekny M and Pekna M: Astrocyte intermediate filaments in CNS pathologies and regeneration. J Pathol 204: 428-437, 2004.

55. Machon O, Backman M, Machonova O, Kozmik Z, Vacik T, Andersen L and Krauss S: A dynamic gradient of Wnt signaling controls initiation of neurogenesis in the mammalian cortex and cellular specification in the hippocampus. Dev Biol 311: 223-237, 2007

56. Zhou CJ, Borello U, Rubenstein JL and Pleasure SJ: Neuronal production and precursor proliferation defects in the neocortex of mice with loss of function in the canonical Wnt signaling pathway. Neuroscience 142: 1119-1131, 2006.

57. L'Episcopo F, Serapide MF, Tirolo C, Testa N, Caniglia S, Morale MC, Pluchino S and Marchetti B: A Wnt1 regulated Frizzled-1/ $\beta$-Catenin signaling pathway as a candidate regulatory circuit controlling mesencephalic dopaminergic neuron-astrocyte crosstalk: Therapeutical relevance for neuron survival and neuroprotection. Mol Neurodegener 6: 49, 2011. 
58. Chacon MA, Varela-Nallar L and Inestrosa NC: Frizzled-1 is involved in the neuroprotective effect of Wnt3a against Abeta oligomers. J Cell Physiol 217: 215-227, 2008.

59. Lie DC, Colamarino SA, Song HJ, Désiré L, Mira H, Consiglio A Lein ES, Jessberger S, Lansford H, Dearie AR and Gage FH: Wnt signalling regulates adult hippocampal neurogenesis. Nature 437: 1370-1375, 2005.

60. Kalani MY, Cheshier SH, Cord BJ, Bababeygy SR, Vogel H, Weissman IL, Palmer TD and Nusse R: Wnt-mediated self-renewal of neural stem/progenitor cells. Proc Natl Acad Sci USA 105: 16970-16975, 2008 .
61. Harada T, Harada C, Nakayama N, Okuyama S, Yoshida K, Kohsaka S, Matsuda $\mathrm{H}$ and Wada K: Modification of glial-neuronal cell interactions prevents photoreceptor apoptosis during light-induced retinal degeneration. Neuron 26: 533-541, 2000.

62. Yi H, Hu J, Qian J and Hackam AS: Expression of brain-derived neurotrophic factor is regulated by the wnt signaling pathway. Neuroreport 23: 189-194, 2012

(c) (i) This work is licensed under a Creative Commons cc) Attribution 4.0 International (CC BY 4.0) License. 